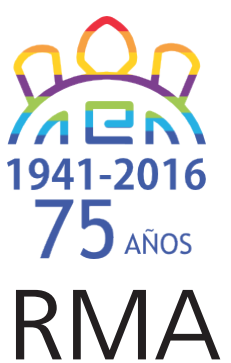

Dossier

\title{
La construcción de un espacio de frontera. Santiago del Estero, el Tucumán y el Chaco desde el prehispánico tardío hasta mediados del siglo XVIII
}

\author{
The development of a frontier region. Santiago del Estero, \\ Tucumán and Chaco from the late pre hispanic period to the \\ mid- XVIIIth century
}

Judith Farberman*

*CONICET, Centro de Estudios de Historia, Cultura y Memoria (CEHCME), Universidad Nacional de Quilmes, Argentina. E-mail: jfarberman@gmail.com

\begin{abstract}
Resumen
El artículo se ocupa del proceso de fronterización del Salado en la larga duración. Se sostiene que en su tramo santiagueño dicho proceso fue tardío -no se registran ataques antes de 1685- y que en el largo paréntesis de relativa paz pudo intervenir la intermediación de los mataraes, un grupo tonocoté encomendado en los vecinos de Concepción del Bermejo y trasladado al Salado santiagueño en 1650. Por sus contactos con los indígenas de tierra adentro primero y su especialización como soldados étnicos posteriormente, el pueblo de indios de Matará funcionó como el núcleo del más importante dispositivo fronterizo de Santiago del Estero durante los siglos XVIII y XIX.
\end{abstract}

Palabras clave: Intermediarios; Río Salado; Santiago del Estero; Matará; Frontera.

\begin{abstract}
The article focuses on the construction of a frontier area on the Salado river over the span of three centuries. It points out that within the borderlands of Santiago del Estero this process was belated - no attacks are known before 1685 - and that these times of relative peace could have been in part related to the brokering role of the mataraes - a tonocote group 'encomendado' by the elite of Concepción del Bermejo and moved to the Salado river in 1650. Because of its relations with the native inland populations first and with the posterior specialization of ethnic soldiers later on, the pueblo de indios of Matará had a central role in the protection of the borderland of Santiago del Estero during the XVIIth and XIXth centuries.
\end{abstract}

Keywords: Brokers; Salado River; Matará; Frontier.

El río Salado, límite oriental de la jurisdicción de Santiago del Estero, fue representado como confín y divisoria cultural desde las primeras crónicas hasta principios del siglo XX. Ya en la Relación de Pedro Sotelo de Narváez de 1583 se recordaba que las aldeas indígenas al servicio de los vecinos santiagueños comenzaban "desde un pueblo que se llama Yocoliguala hasta otro que se dice Colosaca y Calabalax (...) y de ahí abajo están de guerra" (Berberián 1987: 237). La geografía sin pueblos de "ahí abajo" era el territorio de los identificados genéricamente como "indios Chiriguanaes que comen carne humana", los habitantes del Litoral y el Chaco'. Sin embargo, fue

\footnotetext{
1 Como es sabido el rótulo "chiriguano" es una suerte de comodín en las fuentes más tempranas, casi un sinónimo de "salvaje" (cfr. los usos estereotipados de la categoría en referencia a la región de Tarija, Oliveto 2010). En este caso, la alusión es a los grupos chaqueños, luego diferenciados, también genéricamente, como "frentones" por la costumbre común a muchos grupos selváticos de raparse la parte delantera de la cabeza y posteriormente discriminados como mocovíes y abipones -sólo por circunscribirnos a la frontera santiagueña-.
}

sobre todo desde fines del siglo XVII, cuando comenzaron a arreciar los ataques guaycurúes, que la configuración fronteriza del Salado santiagueño apareció en primer plano. Desde entonces, las autoridades coloniales y la vecindad desplegaron un conjunto de políticas ofensivas y defensivas que comprendían, además de las habituales entradas de escarmiento, las reducciones y los fortines, el servicio de los "pueblos de indios cristianos" (Farberman 2004 y 2011; Farberman y Ratto 2015).

Este artículo se propone analizar el proceso de construcción de la frontera chaqueña en el largo plazo y en diferentes escalas. Es un objetivo ambicioso, en la medida en que

\footnotetext{
Abipones y mocovíes pertenecían a la familia lingüística guaycurú aunque el uso del etnónimo sea menos frecuente en las fuentes primarias que manejamos. Sobre el uso de gentilicios diversos para mocovíes y abipones, cfr. Nesis 2005 y Lucaioli 2005. Es posible que también los grupos del litoral -como los calchaquíes de Santa Fe- también entraran en el rótulo temprano de "chiriguanaes" lo que permitiría interpretar el "de ahí abajo" como "al sur".
} 
requiere de la colaboración con otras disciplinas -en particular con la arqueología- y el desafío de lidiar con una historiografía compartimentada por provincias o jurisdicciones administrativas. La escala más amplia, comprensiva del gigantesco espacio chaqueño que limitaba con tres gobernaciones -Paraguay, Tucumán y Buenos Aires- se combinará con otra menor -la relativa al tramo santiagueño del Salado, que conocemos con más detalle- y una tercera más pequeña aún, focalizada en el grupo de los llamados mataraes. Por este motivo, necesariamente, los apartados que estructuran el artículo conllevan sustantivos cambios de enfoque.

Tres recientes líneas de investigación nos servirán de guía. En primer lugar, los trabajos arqueológicos (Angiorama y Taboada 2008; Taboada, Angiorama, Leiton y López Campeny 2013; Taboada 2014, 2016a y 2016 b; Lorandi 2015²), históricos (Castro Olañeta 2013a y 2013b) e interdisciplinarios (Taboada y Farberman 2012, $2014,2015)$ que se han ocupado específicamente de la región del Salado Medio. Entendemos que, tanto el examen de fuentes tempranas como su interrogación a partir de las preguntas de la arqueología, han revelado una complejidad y heterogeneidad que resignifican los procesos posteriores y que esperamos recuperar sumariamente aquí.

En segundo lugar, nos interesan las contribuciones de Silvia Palomeque (2009) por aportar un nuevo paradigma de interpretación de la historia colonial temprana del Tucumán. Desde esta perspectiva, Santiago del Estero forma parte de una región más amplia que incluía también a las fallidas fundaciones de Ibatín y Esteco. Como ha demostrado Palomeque, así como la "destrucción de las tierras bajas" inmediata a la conquista allanó el ascenso de otras zonas, una reconfiguración análoga tuvo lugar en Santiago del Estero, donde la explotación de los recursos naturales y humanos de los pueblos del Dulce había preservado por algún tiempo a los del Salado, donde a principios del siglo XVII se encontraban "situados los más yndios desta jurisdicción" (Castro Olañeta 2013). Aunque este balance demográfico no puede proyectarse posteriormente, es importante pensarlo en el contexto del proceso de conquista y de los avatares del poblamiento en el largo plazo.

Por fin, también son notables los avances de la literatura antropológica sobre los grupos chaqueños de tierra adentro, en particular de los guaycurúes. La relectura de las estupendas monografías jesuíticas de Dobrizhoffer y Paucke sobre abipones y mocovíes desde una mirada más

\footnotetext{
2 El libro de Ana María Lorandi, aunque editado en 2015, es la síntesis de trabajos arqueológicos y etnohistóricos realizados hace treinta años. No obstante, por tratarse de una versión articulada de las dos líneas de investigación que construyeron la trayectoria profesional de la autora y por representar sus trabajos el ingreso de la arqueología moderna en Santiago del Estero, incluimos este texto en la categoría de aportes recientes. Para no multiplicar las citas, los aportes arqueológicos y etnohistóricos de Lorandi sobre el Salado santiagueño serán citados a partir del libro de 2015 que los condensa.
}

sensible hacia las sociedades indígenas ha problematizado y otorgado entidad histórica a pueblos que parecían fuera del tiempo, reconstruyendo sus lógicas materiales y estrategias guerreras (Nesis 2005, Lucaioli 2005 y 2011, Vitar 1997). Estos aportes, además, han habilitado una mirada más completa de las dinámicas fronterizas que, al despegarse de las cabeceras administrativas y proyectarse hacia el interior del Chaco, ilumina el accionar de diferentes actores -caciques, autoridades locales, jesuitas, vecinos, milicianos- con intereses cambiantes y contradictorios.

Además de estos avances, retomaremos también algunas contribuciones propias, solitarias y en colaboración, entre las cuales la hipótesis que postula como colonial el proceso de fronterización del Salado (Taboada y Farberman 2014 y 2015), la consideración de una dinámica fronteriza relativamente autónoma respecto de las políticas "estatales" (Farberman y Ratto 2015). En este juego, reexaminaremos el papel de los mataraes, los "indios cristianos" al servicio de Concepción del Bermejo, trasladados al Salado en 1650, que ya fueron objeto de un trabajo anterior (Farberman 2011). Entre otros actores, este grupo intermediarios nos habilitará el puente entre la escala micro y la macro, incorporando a la historia fronteriza santiagueña regiones muy distantes, situadas en otras jurisdicciones administrativas como Paraguay y Buenos Aires.

Aunque consideremos en conjunto un período extremadamente largo -desde el prehispánico tardío hasta el siglo XIX- serán puntualmente tres los momentos analizados en el trabajo, a manera de postales o fotografías: uno inicial en el cual el Salado no parece señalar una frontera (del prehispánico tardío a la colonia temprana), uno intermedio, hacia 1630, que localiza la frontera saladina hacia el norte y en una dinámica que involucra a Esteco y Concepción del Bermejo, en el interior del Chaco, y un tercero, hacia 1685, de fronterización del Salado santiagueño.

\section{Territorio y diversidad en los albores de la conquista española}

El panorama arqueológico actualmente disponible sobre las poblaciones prehispánicas tardías de nuestra región permite advertir cierta heterogeneidad en sus expresiones, prácticas y modos de relacionamiento. En contraste, mientras algunas fuentes tempranas reconocen esta diversidad -por ejemplo, al discernir lenguas y contraponer modos de vida-, otras la ignoran utilizando rótulos extremadamente genéricos o generalizando determinadas prácticas económicas o guerreras.

Un primer problema surge de la identificación del territorio en cuestión como una provincia mayoritariamente "juri"3.

\footnotetext{
3 Según Palomeque (2013), que retoma parte del argumento de Salas, "los cronistas hablan de "juries" o "zuriés", y los califican de "alárabes", "salteadores", "que comen carne humana" y que andan en "pequeños grupos", de la misma forma que los españoles de Charcas
} 
Esta categoría -que por otra parte excedía largamente al Salado santiagueño- fue en breve desplazada por otros dos rótulos -tonocoté y lule- que designaban a la vez lenguas diferentes (aunque inteligibles según algunos testimonios) e idiosincrasias contrapuestas. En efecto, Pedro Sotelo de Narváez, Jerónimo de Bibar y Alonso de Barzana, entre otros cronistas, señalaron a los tonocoté como habitantes de muchas aldeas indígenas del Dulce y de la totalidad de las del Salado. En contraposición tajante con los lule, de los que se despreciaba el nomadismo la belicosidad, los tonocoté fueron caracterizados como labradores y sedentarios. Por otra parte, los lule, "gente bárbara", de "poca razón" o "mal asentada", fueron sindicados como acérrimos enemigos de los tonocoté, que habían cercado sus pueblos con empalizadas para defenderse de ataques y saqueos ${ }^{4}$.

Por su parte, la arqueología caracterizó a las poblaciones del tardío como grupos ceramistas, con asentamientos reconocibles y economía mixta, sin detenerse en las diferenciaciones a las que apuntaban las fuentes textuales (Lorandi 2015). Recientemente, a partir del análisis de la arquitectura, contenido y estructura de dos tipos de montículos en el sitio de Sequía Vieja (bañados de Añatuya), Constanza Taboada ha conjeturado que pudieron existir en el Salado medio y para el período tardío dos grupos con modos de habitar diferenciados, uno más estable y otro más móvil (Taboada 2016a y 2016b). De confirmarse el uso sincrónico de los dos tipos de montículos, podría plantearse "la cohabitación de gente diferente, al menos, en la forma de construir su hábitat y en la cerámica que usaban" (Taboada 2016a:3) de manera aparentemente acorde con la categorización de las crónicas hispanas 5 . Ello, en cualquier caso, se aparta de una división rígida entre nómades y sedentarios para apuntar a un relacionamiento con el ambiente que combinaba la movilidad con la estabilidad y que no excluía la coexistencia de grupos con identidades diferentes en las mismas aldeas ni la eventual confrontación entre ellos ${ }^{6}$.

se refieren a los chiriguanos o chiriguanaes". En opinión de Lorandi (2015: 70) "parece haber habido una parcial coincidencia entre el concepto y extensión del Tucumán como región, y la identificación de sus aborígenes, que son llamados juries en los documentos más tempranos. Aparentemente, con este nombre se designan a grupos distintos, englobados en el concepto de "nación" en la percepción de los aymaras altiplánicos, quienes lo transmitieron a los españoles de mediados del siglo XVI".

${ }^{4}$ Para Alonso de Barzana, los lules eran una nación "esparcida por diversas regiones como alárabes, sin casa ni heredades, pero tantos y tan guerreros, que si los españoles al principio de la conquista de la provincia de Tucumán no vinieran, esta nación sola iba conquistando y comiendo unos y rindiendo otros y así hubiera acabado a los tonocotés" (Berberián 1987: 79). La descripción de Jerónimo de Bibar es casi idéntica (Berberián 1987:178).

5 Por otra parte, estos grandes sitios con montículos de ambas clases podrían remitir a un "centro de encuentro y congregación habitacional", el respaldo material de aquellos encuentros que los españoles caracterizaron como "juntas y borracheras", ámbito de acuerdos y alianzas políticas entre grupos culturalmente diversos.

${ }^{6}$ De hecho, Ana María Lorandi ya había sugerido hace muchos años que pudieron existieron subgrupos lule parcialmente sedentarios que compartían sus aldeas con los tonocoté "formando comunidades que, si fueron originalmente biétnicas finalizaron por mostrar un alto
Además de la jurí, las fuentes tempranas reconocieron también otras identidades en el Salado santiagueño, utilizando el vocablo "provincia" para señalar las diferencias (Lorandi y Ottonello 1984: 152). En este sentido, dos probanzas de méritos delimitaron otras tres provincias, bien que minoritarias: las de "salabines" y "sanavirones" y la de Guatiliguala. Por ser más acotadas que la jurí, resulta más sencillo localizarlas y ponerla en diálogo con la información arqueológica”. "Salabines", en efecto, remite al todavía hoy existente pueblo de Salavina, en el sur de la mesopotamia santiagueña, "sanavirones" a la región limítrofe con el norte de Córdoba y Guatiliguala al repartimiento de ese nombre -de probable filiación lule- situado en las cercanías de la primera Esteco. En un artículo anterior, reseñamos con cierto detalle el estado actual de los conocimientos arqueológicos de cada una de estas zonas (Taboada y Farberman 2014), por lo que alcanza con recordar que los sitios que podrían asignarse aproximadamente a estas tres provincias comparten una escala relativamente modesta y la ausencia de materiales coloniales, atribuible al abandono anterior -o coincidentecon la conquista española.

Una cuarta zona, ubicada en los bañados de Añatuya, ha sido singularizada con nitidez por la arqueología. Las fuentes escritas no la recortan como provincia específica, pero sí señalan en ella a diversas "naciones" y "parcialidades" rebeldes (Meaxa, Niquindey, Istail, Lasco, Mancapa, entre otras), que luego dieron nombre a sendos repartimientos coloniales. La particularidad de esta zona es que en sus sitios, sobre todo en el de Sequía Vieja, se encontraron con exclusividad objetos de metal y rasgos andinos, así como numerosos bienes ajenos a la tradición local (tupus, lauraques, pichcas) y objetos y rasgos típicos del litoral (pipas, cierta cerámica). Ello ha sugerido un mayor grado de interacción de sus poblaciones con otros grupos -del Chaco, del Litoral y aún representantes del incario-, interacción que incluso habría superado los primeros momentos de la conquista española, como lo demuestran las rebeliones de las ciénagas que analizamos en otra parte y sobre las que volveremos en este trabajo (Taboada y Farberman 2014 y 2015) ${ }^{8}$. Lo que en todo

grado de integración, de tal forma que los observadores españoles tuvieron mucha dificultad para separarlos" (Lorandi 2015: 71). Esta hipótesis encontraría su refuerzo en la citada inteligibilidad mutua de las lenguas lule y tonocoté (utilizada esta última para evangelizar a los dos grupos) y en la transculturación parcial que denota la cerámica hallada en algunos sitios del Salado.

${ }^{7}$ Se trata de testimonios debidos a Hernán Mexía Miraval, miembro de la hueste de Pérez de Zurita, incluidos en tres probanzas de méritos y servicios fechadas entre 1584 y 1585 y referidas a sucesos acaecidos entre 1552 y 1553. Los documentos fueron consultados en CGGV-BN, 152; Levillier 1920: 220-235 y Levillier 1920: 347-367.

${ }^{8}$ La excavación moderna de Sequía Vieja y el análisis de colecciones provenientes de varios sitios aledaños, han permitido a Taboada y Angiorama especular sobre la posibilidad del entable de una relación peculiar entre los grupos de los bañados y el incario (Taboada et allí 2013; Angiorama y Taboada 2008; Taboada 2014). La inmensa cantidad de torteros y objetos de hueso y los citados objetos de metal apuntalarían la hipótesis del interés imperial por una zona apetecible por sus recursos (maderas duras), por las destrezas de su población (producción de textiles y cerámica) y su ubicación protegida. A juicio 
caso queda claro es la formidable capacidad política de los habitantes de los bañados de Añatuya que dejan ver tanto la variedad y magnitud de los bienes hallados como la posterior sobreimposición de pueblos de indios coloniales $^{9}$.

Por fin, a las zonas arqueológicas y a las "provincias" delimitadas por las fuentes españolas podría añadirse la presencia en el Salado Medio de algunos topónimos de origen cacán como Tatingasta y Guañagasta. Como planteamos en otra parte (Taboada y Farberman 2012), lo "diaguita santiagueño" descoloca a la arqueología dada la ausencia de cerámica santamariana en el Salado (existente, aunque de manera muy acotada, en el Dulce). Aunque Lorandi (2015: 78) hipotetizó la presencia de colonos diaguitas trasladados por los incas a las yungas tucumanas, lo cierto es que los sitios de los bañados de Añatuya que contienen evidencias incaicas no albergan un solo registro de cerámica santamariana ni proveen indicios acerca de la instalación allí de gente de los valles (Taboada, comunicación personal).

En resumen, arqueología y fuentes tempranas llevan a pensar en un mosaico de relativa heterogeneidad para la región del Salado santiagueño, al menos hacia el occidente del río. ¿Incluían las mencionadas provincias al territorio que se extendía hacia el este? No se trata de un dato evidente en las fuentes textuales, ni puede darse por descontado ${ }^{10}$. Tampoco la arqueología, al menos hasta donde hoy se sabe, tiene elementos para pensar en este tramo del río como frontera. Por el contrario, la similitud de materiales e instalaciones indígenas a uno y otro lado del Salado indicaría, en principio, su ausencia en tiempos prehispánicos tardíos (Taboada y Farberman 2014). De la misma manera, la presencia de objetos típicos del litoral en sitios santiagueños del Salado y aún de la mesopotamia mostraría una interacción que la supuesta participación de los "chiriguanaes" en las rebeliones de las ciénagas llevaría a reforzar (Taboada y Farberman 2014 y 2015).

\section{Las "ciudades" de las tierras bajas}

La ciudad de Santiago del Estero fue el primer fruto estable de la conquista. Isabel Castro (2013b) ha explicado su fundación y persistencia en el marco de una alianza hispano tonocoté, orientada a conjurar la ya

de estos autores, se habría tratado de alianzas políticas de tenor muy similar a las que los incas habían sostenido con otros grupos de las tierras bajas - y que no implicaban una "anexión" formal al imperio- consolidadas a partir del intercambio de regalos (Taboada y Angiorama 2015).

9 Contamos hoy con suficientes elementos para sostener que en la aldea indígena emplazada en Sequía Vieja se organizó posteriormente el pueblo de indios de Lasco (Taboada y Farberman 2015).

${ }^{10}$ Las fuentes jesuíticas abundan en sorpresa y admiración por la destreza demostrada por los indígenas al cruzar el río, trasladando campamentos, ganados y bienes. Para los españoles, en cambio, el río constituía un obstáculo geográfico y también por eso se refuerza su representación colonial de límite. Agradezco a Carina Lucaioli que me llamó la atención sobre este punto. mencionada amenaza de los lules nómades. Al parecer, en las inmediaciones del río Salado no se replicó un acuerdo semejante. Fue allí donde, según Lozano, "más inquietudes hubo entre los indios (...) cuyos naturales, más montaraces, fiados en el abrigo de sus bosques, se resistían más obstinados a sujetarse y daban mucho ejercicio a nuestras armas" (Lozano 1874: 150).

La narración del jesuita coincide, también en el tono épico, con los testimonios tempranos sobre la resistencia indígena en las "ciénagas"-nombre asignado a los bañados de Añatuya- que retrasaron hasta 1556 la "pacificación" del primer enclave estable en las tierras bajas ${ }^{11}$. Era sólo un anuncio de las dificultades que abundarían en la década siguiente. Hacia 1563, la primera rebelión calchaquí terminó con las precarias "ciudades" de Londres, Córdoba, Cañete y Nieva y las fundaciones que sucederían a las fallidas- Ibatín/San Miguel de Tucumán (1565) y Talavera de Esteco (1567)- también tendrían lugar en las tierras bajas, que irían perdiendo posiciones (hasta desaparecer en los casos de Ibatín y Esteco) en beneficio de las que se erigieron a partir de la década siguiente (Palomeque 2009: 2013).

¿Puede incluirse en esta cartografía de las "ciudades" de tierras bajas a Concepción del Bermejo, poblada en 1585 y destruida en 1633? Entendemos que, no obstante su pertenencia sucesiva a las gobernaciones del Paraguay y del Río de la Plata, la historia de esta malograda fundación se vincula estrechamente con la de Santiago del Estero -especialmente a través del nexo de los mataraes que pasaremos a detallar- y con la de Talavera de Esteco. En efecto, Esteco y Concepción del Bermejo -esta última, equidistante de Esteco y de Corrientes, fundada pocos años antes- intentaban acortar las distancias entre Santiago del Estero, Charcas y el Paraguay y defender de los "frentones" el inestable territorio controlado por las gobernaciones ${ }^{12}$. Una vasta zona de bañados separaba Talavera de Esteco de Concepción, geografía complicada para los españoles pero mucho menos para los indígenas, como lo describió Diego de Ocaña:

\footnotetext{
11 La rebelión de las ciénagas está registrada en las probanzas de Hernán Mexía Miraval de 1584 (En Levillier 1919: 347-367) y en la de Nicolás de Garnica (CGGV-BN, 252). Los pueblos identificados son Lasco, Vilapa y Mancapa (localizados en los bañados) y Meaja (fuera de los bañados). También participaron Istail y Niquindey que no hemos conseguido ubicar. Según Lozano, "sin duda fue mayor proeza la que ejecutaron el año de 1556 los españoles, como que con muy corto numero consiguieron victoria en el mayor peligro en que jamás hasta entonces se habían visto y fue el que ya insinuamos. Porque habiéndose esparcido por todo el Chaco la fama del disgusto con que los indios del Salado, toleraban la sujeción a nuestros dominios, llegó de unas naciones en otras, a noticia de los muy distantes chiriguanos, de los cuales atravesando muchas leguas vino al Salado un numeroso cuerpo fomentar a los saladinos y persuadirles que de una vez sacudiesen el yugo y no dejasen aumentarse la nueva población de los españoles" (Lozano 1874:150).

${ }^{12}$ Concepción del Bermejo ofrecía una ruta más directa entre Asunción y el Tucumán, evitando pasar por Santa Fe. En cuanto a la primera Esteco y a Cáceres, su antecesora fundada por un grupo rebelde, se ha discutido sobre lo fortuito o no de su localización. Según Torre Revello (1943:18), se trataba de una población ya prevista por Matienzo.
} 
"Lo que hay notable es que para pasar deste pueblo [Concepción] a nuestra Señora de Talavera de Esteco hay un pantano de más de dos leguas, el cual hacen los indios cada año. Cuando vienen de avenida los ríos del Pirú, abren por algunas partes las orillas que tienen como diques de Flandes y sale el agua de la madre y tiéndese por todo el campo; y con ella sale mucha abundancia de pescado y para tenelo allí hacen esto los indios; que dura estar esta agua sin enjugarse, cuatro meses. $Y$ todos estos cuatro meses se camina por esta agua, que da de ordinario a la barriga y algunas veces a los arzones de las sillas; y así los que caminan van con calcetas y zaragüelles de lienzo; y los caballos están tan diestros, que andan bien, aunque en todo el día no se caminan más de solas estas dos leguas" (Madroñal Durán y López de Mariscal 2010:202)

Las "naciones" del Chaco atravesaron el "pantano", amenazando en numerosas ocasiones a las dos ciudades, hasta hacerlas desembocar en un común final trágico ${ }^{13}$. En realidad, los devenires de Concepción y de Esteco estuvieron hasta cierto punto conectados, aunque ni siquiera José Torre Revello (1943) -autor de una de las más detalladas monografías sobre las ciudades desaparecidasenfatizara en su articulación. Detengámonos, entonces, en las intersecciones que nos permiten detectar las fuentes y que nos permiten pensar sus historias en un contexto más amplio y relacional.

Por empezar, las crónicas localizan grupos tonocoté y lule (los dos componentes de la categoría "jurí") al servicio de Santiago del Estero y de Talavera de Esteco ${ }^{14}$. En cuanto a los grupos encomendados en los vecinos de Concepción del Bermejo, bien que identificados mayoritariamente con el nebuloso rótulo de "frentones", incluían entre

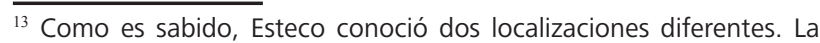
primera, como Talavera de Esteco, al norte del río Salado, es la que más nos interesa por sus conexiones con la historia de Concepción del Bermejo. Fue fundada en 1567 y trasladada como Nuestra Señora de Talavera de Madrid, en las cercanías de Metán, en 1609. El golpe de gracia de la "nueva" Esteco fue el terremoto de 1692. Sin embargo, para entonces, ya hacía décadas que languidecía. Cfr. al respecto Torre Revello 1943, Tomasini y Alonso2001, Tomasini 2008 y Aguilar 2016. ${ }^{14}$ Empero Alonso Barzana y Diego Pacheco destacaban ciertas diferencias idiosincráticas entre tonocotés: mientras para el primero los indígenas del norte del río Salado no vestían a la usanza "peruana" y andaban "cubiertos con unos plumeros de avestruces (....) y ellas con unos pequeños de lienzos poco más de un palmo así en tiempo de calor como de frío" (Berberián 1987: 255-256), para Pacheco, los de Esteco "también son indios Juríes aunque diferentes de lengua y en alguna manera en la nación y vivir (y) se diferencian en el traje" (Berberián 1987: 219). La sentencia de Pacheco coincide con la de Jerónimo de Bibar para quien el "valle de Esteco" era "lengua por sí" (Berberián 1987, 177. Por último, en una información de la ciudad de Talavera de Esteco se contrapone a los yanaconas de chacras y estancias quechua hablantes y a "los indios labradores que tienen por apellido tonocotes" de "lengua general diferente de la del Perú y otras generaciones de lules y frentones (que) tienen muchas diferencias de lenguas". ABNB, CACh 630, 13 vta. Agradezco esta cita a Isabel Castro.
}

sus "indios de servicio" a dos pueblos de "labradores" -Guacará y Matará- de los cuales, por lo menos los segundos, eran de "nación tonoste" (tonocoté)15. Sin embargo, el dato de mayor interés para nuestra argumentación remite al presunto origen foráneo de los mataraes que, según el gobernador del Río de la Plata Diego de Góngora, se encontraba "en la dha provincia de Tucumán de donde se retiraron a este sitio a más de 30 años por cierto delito que en ella cometieron" (Cervera 1907, I: 83-90 ${ }^{16}$. Como sea, todas las fuentes avalan la distinción de los mataraes como "gente labradora" y diferente de sus vecinos chaqueños ${ }^{17}$.

Un segundo cruce apunta a los tempranos conflictos jurisdiccionales que estallaron entre Esteco y Concepción del Bermejo y que revirtieron en disputas sobre la gente a repartir. Cabe recordar que la fundación de la segunda ciudad fue casi simultánea al "descubrimiento" de los labradores de Guacará y Matará. En una célebre misiva dirigida al obispo de Tucumán, el fundador Alonso de Vera y Aragón describió al poblado de nuestro interés en estos términos:

\section{"(...) treinta leguas hasta la boca del rrio Bermejo treynta leguas hasta donde estoy agora poblado, que es esto de matará abre descubierto mas de veynte mil indios jente muy luzía de presente me sirven como dos mil dellos, que son estos de matara, es jente de mucha rrazon e los mejores Labradores que e visto, porque prometo a V.Sa Reberendisima que les halle mas de veynte mil hanegas de maiz. Es belleza las chacaras que tienen". (Torre Revello 1943: XXV-XXVI) ${ }^{18}$}

\footnotetext{
${ }^{15}$ También se nos dice que fue en tonocoté - lengua inteligible también para lules y abipones- que el padre Barzana evangelizó a los mataraes en su localización chaqueña (Del Techo 1673: 186, entre otros). ${ }^{16}$ Cabe destacar que el Chaco aparece como "región de refugio" en diversos textos como los de Xarque, Machoni y Lozano En un listado de principios del siglo XVII publicado por Maeder (1988) se afirma con mayor precisión que "setenta leguas de la Cordillera están poblados sobre los bañados del Pilcomayo a la parte del río Vermejo los indios Tonocotés y lules que se retiraron de la gobernación del Tucumán cuando entraron los primeros conquistadores y pobladores de aquellas provincias. Son más de seis mil indios; tienen grandes sementeras en bañados y tierra firme y grande amistad y comunicación con los indios del Chaco que están de Pilcomayo hacia el norte y son los de los Llanos de Manzo. Ay destos indios a la ciudad de la Assumpcion del Paraguay que esta al este setenta leguas y a la de la Concepción del Rio Vermejo, sesenta leguas". Maeder ubica el sitio en el límite entre Salta y Formosa, muy distante, por ende de Concepción del Bermejo y de Matará. Nos queda, sin embargo, la duda de que los mataraes de Concepción fueron un desprendimiento de estos grupos situados más al norte.

17 Con todo, la valoración positiva de los mataraes iría decayendo con la profundización de los contactos. Mientras que Vera y Aragón no dejaba dudas acerca de la residencia de los mataraes en aldeas, fuentes posteriores atribuirían su "reducción" a los españoles. Para Nicolás del Techo (1673: 188) fue el fundador de Concepción quien los reunió; en una memoria anónima publicada por Pastells (Pastells, 1912: 285), el artífice fue Alonso de Barzana. Una tercera versión, la de Jolís (1972: 281-285) apuntaba que los mataraes habían accedido a reducirse para defenderse de los "abipones".

${ }^{18}$ La ubicación geográfica de Matará es controversial. En su Historia de la conquista, Lozano, basándose en esta referencia, entendió que
} 
Según Torre Revello, esta carta buscaba la intervención del obispo para evitar conflictos de jurisdicción con Esteco. Evidentemente, no consiguió su objetivo: de inmediato, los vecinos de aquella ciudad aseguraron que varios grupos indígenas, ya encomendados y "cristianados" por ellos, se habían rebelado internándose hacia el Bermejo y Vera y Aragón sólo los había "redescubierto" (CGGV-BN, 2883). Finalmente, Matará quedó al servicio de Concepción (y en manos del mismo Vera y Aragón) mientras que el cercano Guacará fue encomendado en un vecino de Esteco, en cuya jurisdicción quedaron también las disputadas parcialidades de Vechipeyajostine, Olmagualamba y Tamalaliguala. El círculo se cerró cuando después de la destrucción de Matará y Concepción, la encomienda de Matará recayó en el nieto de la viuda de Vera y Aragón, un santiagueño que instaló al grupo en el Salado. Pero para entonces los expertos labradores habían reducido drásticamente su número.

Por último, otro punto en común entre Esteco y Concepción es que las hostilidades indígenas provinieron tanto de los grupos presuntamente sometidos como de aquellos que nunca llegaron a repartirse, o sólo lo fueron nominalmente. Noticias escuetas nos informan que un grupo de indígenas al servicio de Esteco exiliado tierra adentro había huido "por haber muerto a un mancebo que entre ellos estaba por poblero" (CGGV-BN, 2883) mientras que un episodio similar, aunque mejor conocido, se repitió en vísperas del final de Concepción cuando:

"rendidos ya totalmente los indios al trabajo, intentaron sacudir el yugo de sus hombros y a este fin, se coligaron con los gentiles de varias naciones, como fueron lagunas, hohomas, frentones y calchaquíes que fraguada con impenetrable secreto la conjuración, asaltaron improvisadamente la ciudad, matando algunos españoles y entre ellos uno o dos sacerdotes y a otros que aprisionaron pusieron en las manos una rueca para que hilasen en despique de lo que en aquel ejercicio los habían molestado para sus granjerías" (Lozano 1745, III, 421).

En el mismo sentido, la masacre de un grupo de mogosnas a manos de los mataraes -que tomó por sorpresa al mismo Alonso de Vera y Aragón- da cuenta de la fragilidad del

Matará se hallaba a treinta leguas de la boca del río Bermejo, mientras que para Torre Revello (1943: 135-136) aquellas treinta leguas corrían entre el pueblos de indios y Concepción. No obstante, las informaciones posteriores, su atribución a ruinas cercanas a los parajes de El Destierro y Tolosa (que habrían correspondido respectivamente a Concepción del Bermejo y Matará o Guacará), la escasa cartografía localizada y el papel del pueblo en la logística de la conquista no es consistente con estas interpretaciones. Las cartas de Diego Marín Negrón (reseñada en Torre Revello 193: 144-145) y Diego de Góngora de 1622 (Cervera 1907, I: 83-90) señalan para Matará una distancia de entre cuatro y siete leguas respecto de Concepción. Por otra parte, las ruinas de un poblado indígena halladas por Tomasini y su equipo "que se sospecha correspondería a Guacará o a Matará" (Tomasini 2008:29) se sitúan a unos 38 km de los restos de Concepción, distancia equivalente a las 7 leguas expresadas en las fuentes citadas. dominio hispano en el interior del Chaco (Cervera 1907, t. I, 83-90).

Sin embargo, este conjunto de testimonios no alcanza para afirmar el asedio permanente de las dos ciudades. En rigor, la información concreta que hemos reunido sin pretensiones de exhaustividad- permite advertir que existieron paréntesis de calma y también simultaneidades en los ataques. Por ejemplo, aunque hacia 1592 veintiséis años después de la fundación de Esteco y siete después de la de Concepción- la supervivencia de ambas fundaciones fue amenazada por los "infieles", no se mencionan nuevos asaltos hasta 1620. El mismo traslado de Esteco a su nueva sede cercana a la actual Metán en 1609 no hace referencia a la hostilidad indígena como causal y, hasta donde podemos reconstruir una cronología, el crescendo de embates tuvo lugar entre la segunda y la tercera década del siglo XVII -con el final de Matará y Concepción en 1631 y 1633 respectivamente- y desde 1664 -fecha del saqueo de Talavera de Esteco o Esteco II- en adelante.

Entramos así en la tercera década del siglo XVII, momento en que la precaria colonización existente tuvo que combatir en varios frentes a la vez (Maeder 1987). En efecto, la destrucción bandeirante de las misiones guaraníes del Guayrá y de las sierras del Tape (1628 -1631), el despoblamiento de Ciudad Real y Villa Rica en el Paraguay y el estallido rebelde en los valles Calchaquíes del Tucumán (1630-36) confluyeron con la caída de Concepción del Bermejo y el declive de la ya trasladada Esteco. Aunque se tratara de regiones muy distantes entre sí, el Chaco, aún menos controlado que antes, funcionaba como un corredor que las fuerzas españolas, ya muy debilitadas, no estaban en condiciones de vigilar. La coyuntura de 1630 abrió un período crítico para los vecinos de Santa Fe y, en líneas generales, una retracción del espacio colonial que sólo comenzó a revertirse, muy tímidamente, medio siglo después. La entrada del gobernador Angel Peredo de 1673 es una de las señales de tal recuperación de la ofensiva.

En un contexto tal, es notable es que no hayamos no hemos encontrado menciones de ataques contra las fronteras santiagueñas hasta $1685^{19}$. Es cierto que las fuentes sobre el siglo XVII no abundan para esta jurisdicción y que también son muy pocas las actas

\footnotetext{
19 Una afirmación de Dobrizhoffer (1970: 46-47) podría abonar parcialmente nuestra hipótesis. Según el jesuita, los abipones no se había atrevido "a atacar desde un principio a los vecinos de Santiago del Estero" al tiempo que "las demás ciudades de Paracuaria estaban en permanente lucha con este enemigo". En diálogo con el teniente de gobernador Barreda, la paz se debía a la comunicación que existía entre los "santiagueños" y los abipones. Sólo cuando los cazadores de ciervos santiagueños traicionaron a los abipones llevándose sus caballos, los bárbaros, sublevados por esta injuria y siguiendo los rostros de los ladrones, comenzaron a recorrer y conocer la provincia de Santiago primero, para luego atacarla con las armas". Por cierto, la cita no es del todo concluyente porque los mocovíes y calchaquíes se adelantaron en los abipones en sus ataques contra Santiago del Estero y Dobrhizhoffer esquiva la precisión en las fechas.
} 
capitulares conservadas. Así y todo, insistimos, sigue siendo llamativo. ¿Pudo influir la mudanza de los mataraes santiagueños en esta relativa paz? Sólo podemos conjeturarlo, ya que el periplo del grupo entre 1629 cuando la aldea chaqueña es destruida- y 1650 -cuando los mataraes son reducidos en la localización actual de Villa Matará- es bastante incierto ${ }^{20}$. En todo caso, es seguro que, desde su reducción santiagueña, estos "indios cristianos" protegieron las fronteras y lo seguirían haciendo en adelante. Anticipemos que, con Matará a la cabeza, esta zona intermedia del Salado santiagueño sería además la que con exclusividad conservaría pueblos de indios de entidad demográfica significativa hasta el siglo XIX.

Por otro lado, sabemos con certeza que no todos los mataraes chaqueños se trasladaron a la nueva sede, lo que aporta más elementos a nuestra hipótesis. Después de la destrucción de la aldea indígena y de Concepción, el grupo se dispersó y tocó al heredero de la encomienda -el vecino santiagueño Felipe de Argañaraz- volver a reunirlo e iniciar la mudanza ${ }^{21}$. Se trataba de un centenar de tributarios (de los cuales una parte pertenecía a la Real Corona), que aportaban unos 500 pesos de renta por lo que un cálculo optimista evaluaría al grupo trasladado en unas 500 personas $^{22}$. Por algún tiempo, las "parcialidades" del Chaco y la santiagueña mantuvieron el contacto. En este sentido, un penitente matará le habría confiado a su confesor el jesuita Pedro Orduña que:

"ay oy en el dicho pueblo de los Mathalas una parcialidad de gente que se vinieron al Salado por aver tenido enfados con sus mismos parientes y llegaron a tomar las armas unos contra otros y los que quedaron allá estarán como quatro jornadas de Ma[ta]la y hasta agora no han hecho las amistades y con esta gente es forsoso encontrar primero para yr a los abipones"23

\footnotetext{
${ }^{20}$ Según Lozano, luego de la destrucción de Concepción del Bermejo el pueblo pasó a la jurisdicción del Tucumán y fue el gobernador Gutiérrez de Padilla quien decidió su traslado en 1645, con el objeto de resguardar a los mataraes de sus enemigos. Ocho años antes, la encomienda de Vera y Aragón había pasado a manos del nieto santiagueño de su esposa, Felipe de Argañaraz, uno de los hijos menores del fundador de Jujuy. Cfr. Farberman 2011.

21 Según un vecino de Santa Fe, "de Corrientes y de otras partes por orden de Argañaraz se sacaron más de treinta indios "de su encomienda de nación matarás y mogosnas que andavan derramados y desnaturalizados desde la despoblación de la ciudad del Río Bermejo y su Reducción de Matará y los trajeron a esta ciudad y estos indios y otros más que recogió el dho don Phelipe de dha su encomienda Los tubo en esta ciudad. En el paraje de los Calchines, jurisdicción Della y otras partes comarcanas y de todos se valía para las vaquerías y otras diligencias que tuvo hasta que se fue a vivir a Santiago donde reside" (Zapata Gollán 1966: 32). Para Lozano (1874, I, 106), después de la destrucción de su asentamiento chaqueño, los mataraes se convirtieron en "el blanco de las vejaciones de los otros infieles, que tiraban a despojarles, así de la preciosa joya de su fe, como de la gloria de incontrastable lealtad, envolviéndolos en su rebelión".

${ }^{22}$ Se trataba, por cierto, de una cifra ya bastante lejana de los más de 900 registrados por Góngora en 1622 (por no hablar de los 20.000 que dijo encontrar -lo que es muy dudoso- Vera y Aragón).

${ }^{23}$ P. Pedro Orduña, "Memorial" (1689) ARSI, Paraguariae 11
}



Figura 1: Fragmento del Mapa "Paraquaria vulgo Paraguay: cum adjacentibus" (1632), atribuido a Luis Ernot S.J. En Atlas Major, Joanne Blaeu, Amsterdam, 1667. (Castro Olañeta 2013b:14).

Figure 1: Fragment of the Map "Paraquaria vulgo Paraguay: cum adjacentibus" (1632), attributed to Luis Ernot S.J. In Atlas Major, Joanne Blaeu, Amsterdam, 1667. (Castro Olañeta 2013b: 14).

La sentencia importa porque hasta podría insinuar alguna iniciativa indígena en la mudanza, motivada tal vez por el mentado conflicto "entre parientes". Por otra parte, el mismo penitente le había aconsejado a su confesor que "entrara a los abipones" desde Corrientes visto que "los matalas iban y venían entonces a los pueblos de los abipones y lo contaron", poniendo en cuestión una vez más la presunta hostilidad constante entre frontones e "indios labradores" recurrente en los documentos hispanos.

La colaboración de los mataraes con los españoles en su antigua y nueva localización vuelve a interpelarnos sobre la falta de registro de hostilidades hasta 1685. Es significativo que en Santiago del Estero reinara la paz mientras en 1655 los ataques contra Santa Fe eran casi cotidianos -al punto de trasladar la ciudad hacia el sur en 1661-. ¿Pudo ser la estratégica "amistad" de los mataraes -con sus componentes de ayuda militar y 
utilización del pueblo como base de operaciones para las entradas ofensivas y las misiones religiosas tierra adentro, a más de los contactos con grupos chaqueños no reducidos - la que apartó a los guaycurúes de esta zona? Cuando, finalmente, los ataques de calchaquíes, mocovíes y abipones alcanzaron también la frontera santiagueña en 1685, los puntos de penetración fueron los extremos norte y sur de la jurisdicción: una vez más, Matará quedaba a salvo de las "ofensas"24.

\section{Los mataraes entre Yuquiliguala y Lasco}

Ya sabemos que el derrotero de los mataraes entre Concepción y Santiago llegó a su fin en 1650. El lugar definitivo donde fueron instalados se situaba en una región intermedia del Salado santiagueño, equidistante a unos 100 km de los dos grandes bañados de Figueroa al norte y de Añatuya al sur. No están claros los motivos que finalmente inclinaron a las autoridades o al encomendero Argañaraz a reducir allí a los mataraes, ni por qué razones fueron abandonadas las anteriores localizaciones cercanas a Yuquiliguala y a Meaxa. Lo que nos interesa resaltar es que esta región intermedia sería la única que -no sin vaivenes- prosperaría en el siglo XVIII, convirtiéndose en un dispositivo defensivo destinado a adquirir cada vez mayor preeminencia. En contraste, a la par que Matará acrecentaba su importancia en la línea del Salado, las antiguas zonas de pueblos de los bañados se perderían definitivamente y exigirían de las autoridades y de la vecindad políticas fronterizas alternativas.

Estamos en condiciones de postular que los pueblos de indios de los bañados - del norte y del sur-fueron los afectados en primer lugar por la (tardía) fronterización colonial del Salado entre 1685 y 1730. La primera señal puede relacionarse con el abandono de la zona norte del río, luego de la caída de Concepción del Bermejo y Esteco. Es de notar que, hasta 1710 -cuando se funden las reducciones de Valbuena y Miraflores- no existirá equipamiento fronterizo alguno, a menos que consideremos como tal al pueblo de Yuquiliguala, luego trasladado a las proximidades de Matará y reconvertido en fortín ${ }^{25}$. En este sentido, es significativo que desde

\footnotetext{
24 Según pudimos reconstruir, los jesuitas Barzana y Añasco se establecieron en Matará hacia 1590 o 1591 con la intención de internarse tierra adentro y acudir a los "frentones". La guerra dejó finalmente inconclusa la misión y sus continuadores -en fecha que no conseguimos establecer- fueron otros dos sacerdotes, Juan Pastor y Gaspar Cerqueyra, el segundo de ellos oriundo de Concepción del Bermejo. También entonces el refugio elegido fue Matará, donde los jesuitas se proponían "tomar guías para llegar a las tierras de Abipones" (Lozano 1941, 183).

25 La localización de Yuquiliguala en la zona de los bañados de Figueroa ha sido propuesta por Isabel Castro Olañeta (2013b), a quien seguimos en la argumentación. No conocemos con precisión el momento de traslado del pueblo pero por lo menos desde 1689 comienza a identificarse a la antigua reducción como fuerte y lugar de castigo. En su carta al Rey, el gobernador de Tucumán Tomás Félix de Argandoña informaba que "la ciudad de Santiago del Estero, cabeza de esta provincia, es una de las citadas y que a padecido en los pueblos de indios de su jurisdicion antes que Yo la governasse muchas desgracias de muertes y robos de mano de dhos Enemigos
}

1685 y hasta principios del siglo XVIII las fuentes hagan referencia a la "frontera de Yuquiliguala", quizás porque desde allí entraban los mocovíes. Los vecinos de Santiago, por su parte, sólo se harían cargo de defender el extremo norte de su jurisdicción a partir de 1734, fecha de la reducción de San Josep de Vilelas, en tierras del destruido pueblo de Asogasta y cercano al antiguo Yuquiliguala de los bañados ${ }^{26}$.

En cuanto al extremo sur del Salado santiagueño, los dos pueblos más mencionados como punto de penetración de los abipones (y con anterioridad de los calchaquíes santafesinos) son Calabalax y, ya en la primera década del siglo XVIII y hasta 1730, Lasco. En rigor, Calabalax desaparece prematuramente de las fuentes: un documento de 1589 denuncia su "vaciamiento" por parte de los vecinos de Santa Fe que disputaban la encomienda ${ }^{27}$. En cuanto a Lasco, páginas atrás lo identificamos como el pueblo más importante de los bañados de Añatuya, cuya historia inicial es por primera vez trabajada desde la arqueología. Cabe destacar que el equipo de Taboada ha encontrado por el momento escasos vestigios coloniales posteriores a fines del siglo XVII, lo que sugiere el abandono del lugar, aunque sólo hacia mediados del siglo XVIII sabemos con certeza que el pueblo se hallaba destruido y dispersa su escasa gente ${ }^{28}$.

Por fin, si los vecinos santiagueños descuidaron la frontera norte de su jurisdicción, en los bañados del sur los fortines no tardaron en erizar la zona, confiriéndole una fisonomía social particular. Mancapa, Colosaca, tal vez Lasco mismo, devinieron fortines y más tarde se erigieron allí El Chincho, Navicha y El Bracho (Di Lullo 1941; Díaz de Raed 1979). En resumen y a manera de balance, hacia fines del siglo XVII las dos zonas de pueblos santiagueños situadas en los bañados del Salado, otrora de significativa envergadura

Mocovíes y en particular el que Ilaman de Yuquiliguala. Dispuse con su Cavildo y Vecinos se cercase este pueblo de Tapias y solo quedase una puerta y en ella un Quartel, para que assista una Esquadra de ocho soldados españoles, que la dha Ciudad a echo obligazn. De pagarlos y darles municiones y Cavallos solo por el tiempo que yo governare y no más".(Torre Revello 1941, I. 374-78. 376). En su nueva localización, el pueblo de indios de ese nombre siguió existiendo y se lo registra incluso en las revisitas borbónicas de finales del siglo XVIII.

${ }^{26}$ La apuesta de la fundación de San Josep de Vilelas era la de cerrar a partir de la localización de "indios pedestres" el ingreso de los ecuestres guaycurúes. Es una de las hipótesis desarrolladas a lo largo del libro de Vitar 1997.

${ }^{27}$ Lope Bravo, uno de los testigos, denunciaba haber "visto huella de caballos herrados mas adelante un poco del pueblo de calabalaje (Calabalax) indios de la encomienda de Juan Díaz Caballero vezino desta ciudad y los naturales de aquellos pueblos dezian e dizen como los de santa fee pueblos del Rio de la plata los an llevado y despoblado los dichos pueblos y llevadolos a santa fee pueblos del rio de la plata". CGGV-BN, 2561.

${ }^{28}$ En 1692 todavía se registra a Lasco como cabecera del curato del mismo. Sin embargo, la descripción trasunta decadencia: Lasco sólo reunía 30 indios "entre reservados y tributarios" y la iglesia se había derrumbado hacía un año y medio. Los restantes pueblos del curato se hallaban aún en peores condiciones: Alagastine tenía unos 10 indios, Mancapa 7, Mamblachi 6 e Icaño 8. Lonsaia directamente había "perdido forma de pueblo". El párroco se lamentaba en su descripción de los inconvenientes que ocasionaban los bañados para las tareas pastorales (Larrouy 1923: 376-377.) 


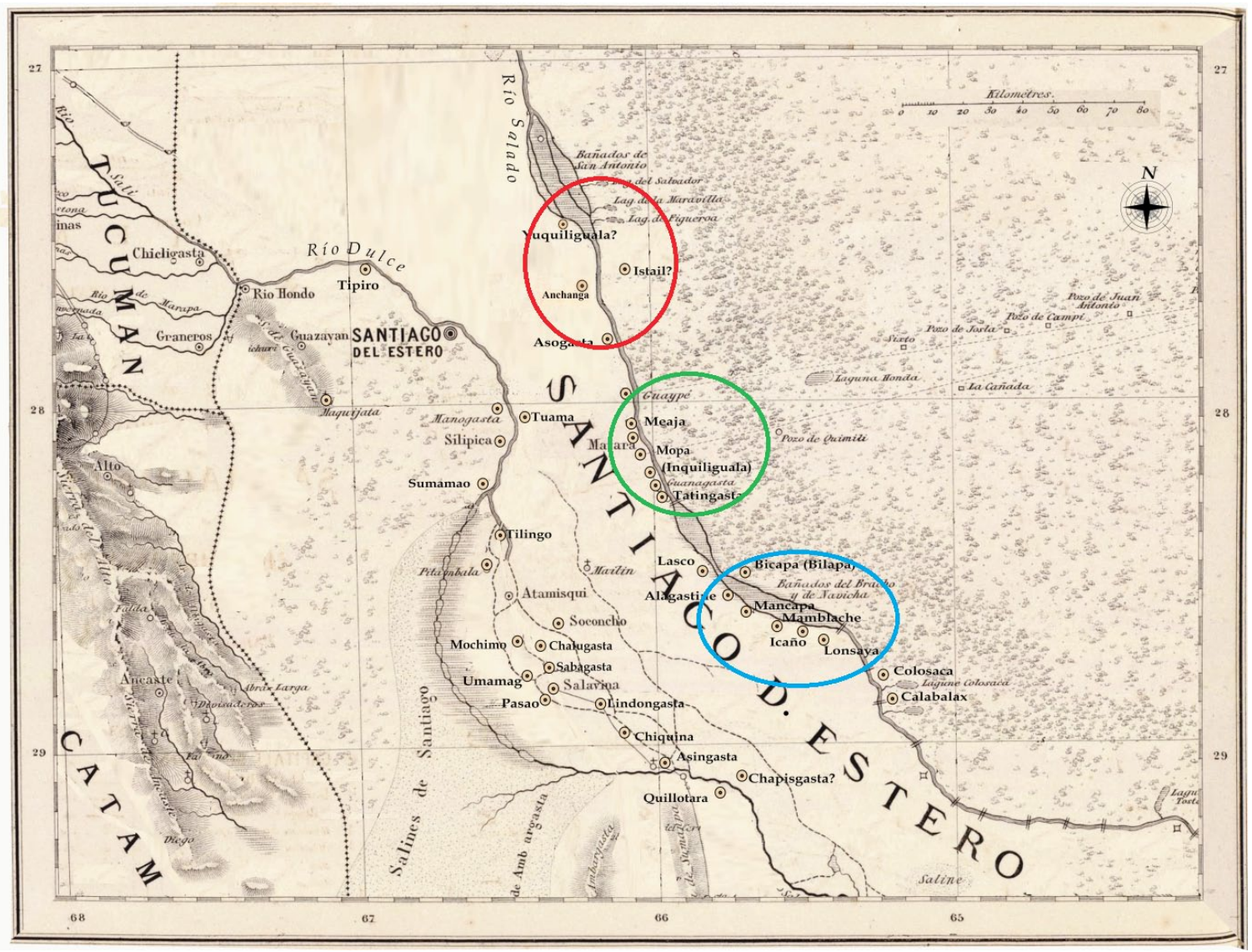

Figura 2: Mapa de la ubicación aproximada de los pueblos de encomienda de los partidos del Río Dulce y del Río Salado. Santiago del Estero, siglo XVII, elaborado sobre la base de "Carte Province de Santiago del Estero Grand Chaco" de Martin De Moussy, 1873 (Castro Olañeta 2013b:13).

Figure 2: Map of the approximate location of the encomienda towns of the Río Dulce and Río Salado parties. Santiago del Estero, 17th century, elaborated on the basis of "Carte Province of Santiago del Estero Grand Chaco" by Martin De Moussy, 1873 (Castro Olañeta 2013b: 13).

demográfica heredada del período prehispánico, se encontraban ya prontas a desaparecer. A un siglo y medio de la conquista, sólo el núcleo central seguía en pie y en ella, muy velozmente, Matará superó en importancia a Tatingasta, otrora el pueblo de indios más nutrido en términos demográficos. En efecto, cuando el visitador

Luján de Vargas se entrevistó en 1693 con los tributarios de la encomienda de Matará, estos dijeron tener "pueblo que es el de maior de gente que ay en esta jurisdicción" y ser "mui cuantiosos". De esta preeminencia quiso también dar cuenta Argañaraz, atribuyendo a su celo el hecho de que mientras "los demás pueblos an ido en disminución ha ido el de matala en mucho aumento". Congregados en torno de la bien alhajada capilla que señoreaba la plaza, los mataraes formaban parte de un verdadero complejo productivo que integraba los cultivos en las sementeras del pueblo, los hilados y tejidos en que se tributaba y la recolección de productos del monte, todo ello bajo la supervisión del hermano del feudatario y de un cruel poblero que los indios se encargaron de denunciar. Además de los maltratos y de las deudas impagas, las quejas apuntaron a la prohibición "de tener con otras personas sus tratos y les compra la miel y cera dándoles menos de lo que valen los géneros", reclamo que se extendía a los textiles que el encomendero pretendía acaparar incluyendo las prestaciones en el tributo o comprando compulsivamente ${ }^{29}$. Por tanto, la traumática experiencia colonial había entrenado a los mataraes en la lidia con los españoles. Podríamos extendernos sobre el posterior devenir de Matará, pero ya lo hemos hecho en otros trabajos (Farberman 2004 y 2011). Basta con recordar que el pueblo se configuró como el principal dispositivo de defensa de este sector de la frontera y que, junto a las demás del Salado, ya situados todos en la zona central, fueron exentos de tributo desde fines del siglo XVIII a cambio de las prestaciones militares aportadas.

¿Por qué motivos Matará -y en menor medida los demás pueblos de su zona de influencia- perduraron y crecieron mientras que los de los bañados decayeron

\footnotetext{
${ }^{29}$ Argañaraz retrucó en su descargo esta afirmación. En sus palabras, las telas se destinaban "lo más para los tratantes que entran a dho pueblo con quienes los yndios se empeñan para sus menesteres", ABNB, EC, 1694.
} 
hasta extinguirse? La pregunta es doblemente importante, visto el papel extraordinario que, como se dijo ya, habían jugado por lo menos los pueblos de los bañados de Añatuya (no tenemos referencias de los del extremo norte) tanto durante el incario como los primeros años de la conquista, cuando protagonizaron aguerridas rebeliones contra las huestes españolas (Castro Olañeta 2013b, Taboada y Farberman 2014). No tenemos una respuesta concluyente, pero sí algunas conjeturas que proponer al respecto.

En primer lugar, podríamos especular, siguiendo el citado memorial del jesuita Orduña, que los mataraes siguieron cumpliendo una función intermediaria con los grupos de tierra adentro. Ya se dijo que, en los momentos iniciales del traslado, los santiagueños mantenían sus contactos con los abipones y con sus "parientes" del Chaco prolongando, al menos por un tiempo, el rol que habían jugado en Concepción del Bermejo ${ }^{30}$. No obstante, esta articulación no podía sostenerse indefinidamente y los mataraes se refuncionalizaron como soldados. Aunque fueran "amigos de irse a los montes" y se especializaran como recolectores de miel, cera y grana compitiendo y confluyendo con los grupos "infieles", su lugar más importante en el siglo XVIII fue el de defender este sector

del Salado de las entradas de los abipones, en las que participaban con sus propias armas. En suma, perduraron y crecieron por ser "indios amigos" y porque los vecinos santiagueños vieron en ellos una forma económica y sencilla de proteger el sector central de la línea del Salado.

En segundo lugar, podríamos asumir que los vencedores terminaron apostando por una zona sin bañados para instalar sus complejos productivos encomendiles. En efecto, un ambiente que en tiempos prehispánicos quizás las sociedades indígenas valoraran por su mayor riqueza relativa y condiciones de seguridad, podía volverse una verdadera pesadilla para los españoles (como lo explicitó el párroco del curato de Lasco en 1692, como lo decía Ocaña para los bañados del Chaco). En este sentido, los conquistadores ya habían conocido la dificultad durante las rebeliones de las ciénagas y nuevamente rechazaron los bañados cuando optaron por relocalizar la reducción de San Josep de Vilelas.

De esta forma, la línea fronteriza del Salado -que como demostramos en otra parte fue defendida casi exclusivamente a partir de esfuerzos locales (Farberman y Ratto 2015)- basó su defensa en fortines en el extremo sur (fortines que primero se autonomizaron de los pueblos de indios para terminar reemplazándolos) y descansó en las reducciones indígenas en el sector central con eje en Matará. Fue desde esa zona que se penetró hacia el Chaco para emprender operaciones militares y misionales y en ello los mataraes se mantuvieron como intermediarios fundamentales.

\footnotetext{
${ }^{30}$ De la misma manera que "comunicaban" los abipones reducidos y los que no lo estaban. Agradezco a Carina Lucaioli por esta observación.
}

\section{Epílogo}

Desde principios de la colonia, la jurisdicción de Santiago del Estero se percibió dividida en tres regiones: la que bañaba el río Dulce, la del Salado y la de la sierra. Estas divisiones cristalizaron en "partidos de pueblos de indios" coincidiendo aproximadamente, como ha apuntado Castro Olañeta (2013b:7), con las "antiguas diferenciaciones espaciales y ambientales intuidas por los primeros cronistas que marcaban diferencias entre las sociedades indígenas del río Dulce, del Salado y de la Sierra".

Los pueblos de indios situados sobre el río Dulce incluían algunos repartimientos muy populosos como los de Tuama, Soconcho y Sabagasta, que persistieron hasta el siglo XIX. Hasta el nombramiento de Ramírez de Velasco, los primeros gobernadores del Tucumán se sirvieron de Soconcho, Manogasta y Anga como privilegio por el cargo que detentaban; de éstos y de otros pueblos situados sobre el Dulce se extrajeron también

los mitayos para el servicio de la ciudad (limpieza de acequias, reparación de edificios públicos, trabajo en chacras, etc.). En contraste, en las sierras de Sumampa y Maquixata parecen haberse conformado desde el inicio escasos pueblos de indios. A fines del siglo XVII, ya no los había en Sumampa y sólo cinco -todos sin iglesia, dos desiertos por completo- existían en Maquixata. En el conjunto de partidos santiagueños, la especificidad del Salado pasó precozmente por su carácter fronterizo: de esa construcción colonial y de sus hitos hemos intentado ocuparnos en este trabajo.

Carina Lucaioli y Lidia Nacuzzi (2014: 28) han caracterizado a las fronteras coloniales como "los espacios de interacción entre los sectores hispanocriollos y los grupos nativos, cuyos límites geográficos y culturales -difusos, múltiples y dinámicos- se definían a través del contacto, la negociación interétnica y los mestizajes". Pensar las fronteras como "espacios de interacción" implica detenerse en el surgimiento de nuevas formas de relacionamiento, en escenarios que fueron ganando en complejidad por aporte de nuevos actores (grupos reducidos y no, "indios cristianos", misioneros, estancieros, milicianos, etc.) a lo largo del tiempo. En este artículo, sumando contribuciones de autores y disciplinas diferentes intentamos dar cuenta de esa complejidad, articulando distintas escalas de análisis.

Si la arqueología nos sugiere que el río no aparece como una clara divisoria entre sociedades diferentes durante el período prehispánico tardío, el fenómeno colonial sí terminaría por introducir una frontera en el Salado, con todas las connotaciones -intercambios, guerra, creación de instituciones y dispositivos fronterizos- que ello implica. Para rastrear de qué manera se construye esa frontera, nos pareció útil partir del momento mismo de la conquista hispana (e incluso un poco antes), cuando 
es posible percibir una heterogeneidad inicial que luego aplanan la documentación y, seguramente, por su carácter homogeneizador, también los mismos procesos coloniales. Por supuesto que las fuentes no deben tomarse a la letra: en este sentido, la investigación arqueológica está permitiendo desmontar las rígidas divisiones de las categorías de los cronistas (nómades y sedentarios / cazadores y labradores / indios de paz y de guerra) y por eso es valioso el intercambio entre disciplinas.

En segundo lugar, quisimos insertar la región del Salado santiagueño en otra mayor. Esta escala supone un territorio que fue moldeándose a partir de la intervención de políticas de ocupación del espacio simultáneamente fundacionales, mercantiles y defensivas. Estas intervenciones delimitaron geografías que trascendían los límites administrativos convencionales. Siguiendo a Palomeque, insertamos en nuestro mapa a Talavera de Esteco y pensando en los criterios que ella sugiere consideramos que también Concepción del Bermejo formaba parte de ese sistema urbano inicial de las tierras bajas y que su fundación contribuye a configurar una frontera -bélica y aguerrida- en el Chaco.

Habitualmente, se piensa la frontera tucumano chaqueña como un producto del siglo XVIII (o de finales del anterior), porque es entonces que se activan las políticas ofensivas y defensivas a diversos niveles del estado o -como hemos planteado en otra parte (Farberman y Ratto 2014)- por iniciativas de los mismos actores locales (sacerdotes, estancieros, comerciantes). Sin embargo, las historias conectadas y trágicas de Talavera de Esteco y Concepción del Bermejo permiten alargar hacia atrás el proceso de fronterización. Si la consideración de este conjunto de tres ciudades nos proporciona una escala macro, la focalización en los mataraes -ligados a las vicisitudes de los tres espacios- permite un abordaje a escala micro. La tercera parte de este artículo procuró transitar ese camino. Se abocó a la reconfiguración de la frontera tomando en cuenta las políticas -en las que el sector de pueblos de indios nucleado en torno de Matará se convirtió en el más importante- y especulando también sobre otros factores que pudieron jugar en la destrucción de los núcleos de los bañados. El problema queda abierto y se proyecta hacia el siglo XIX, con la transformación del pueblo indígena en un activo enclave criollo.

Buenos Aires, 25 de octubre de 2016

\section{Agradecimientos}

Este texto se ha beneficiado de las lecturas de Isabel Castro Olañeta, Constanza Taboada y Carina Lucaioli. Agradezco también los comentarios de Silvia Ratto y Raúl Fradkin a una versión anterior de este artículo que me ayudaron a conseguir esta versión final. El mapa de De Moussy con el agregado de los pueblos de indios santiagueños fue confeccionado por Isabel Castro Olañeta y Leticia Carmignani que gentilmente me han permitido reproducirlo.

\section{Abreviaturas}

ABNB: Archivo y Biblioteca Nacionales de Bolivia, Sucre, Bolivia

CGGV-BN: Colección Gaspar García Viñas, Biblioteca Nacional Argentina, Buenos Aires, Argentina

\section{Bibliografía citada}

Aguilar, N. 2016. Los lule del Pasaje Balbuena. La frontera chaqueña occidental. Siglos XVII y XVIII. Rosario: Prohistoria.

Angiorama, C. y Taboada, C. 2008. Metales andinos en la llanura santiagueña (Argentina). Revista Andina, 47,117-150.

Berberián, E. 1987. Crónicas del Tucumán. Siglo XVI. Córdoba: Comechingonia.

Castro Olañeta, I. 2013a. La Numeración de los indios del partido del Río Salado. Santiago del Estero, 1607. Encomiendas y servicio personal. Corpus. Archivos virtuales de la alteridad americana: 3:2. http://corpusarchivos.revues.org/535 y http://corpusarchivos. revues.org/535\#annexes (Última consulta: 10/10/2016)

Castro Olañeta, I. 2013b. Donde están situados los más indios de la jurisdicción de esta ciudad. Un acercamiento etnohistórico a las encomiendas y pueblos de indios del Río Salado. Santiago del Estero entre fines del siglo XVI y principios del XVII": Surandino Monográfico: 3:2. http://revistascientificas.filo.uba.ar/index. php/prohals/article/view/477/465 (Última consulta: 10/10/2016)

Cervera, M. 1907. Historia de la ciudad y provincia de Santa Fe 1573-1853. Tomo I. Santa Fe: Librería La Unión.

Charveloix, P. 1910 (1756). Historia del Paraguay Con las anotaciones y correcciones latinas del P. Muriel. Madrid: Librería de Victoriano Suarez, Tomo I.

Del Techo, N. 1897 (1673). Historia de la provincia del Paraguay de la Compañía de Jesús. Madrid: Librería y casa editorial de Uribe, y Cia. Tomo II.

Díaz de Raed, S. 1979. Hombres y fortines de Santiago del Estero. Santiago del Estero: Museo Histórico de la Provincia.

Di Lullo, O. 1949. Reducciones y fortines. Santiago del Estero: Francisco Rossi.

Dobrizhoffer, M. 1970 (1791). Historia de los Abipones, Santa Fe: Imprenta de la Universidad Nacional del Litoral, tomo III.

Farberman, J. 2004. Curacas, mandones, alcaldes y curas. Legitimidad y coerción en los pueblos de indios de Santiago del Estero, siglos XVII y XVIII. Colonial Latin American Historical Review, 13: 4: 367-397.

Farberman, J. 2008. Santiago del Estero y sus pueblos de indios. De las ordenanzas de Alfaro (1612) a las guerras de independencia. Andes. Antropología e historia: 19: 225-250.

Farberman, J. 2011. Entre intermediarios fronterizos y guardianes del Chaco: la larga historia de los mataraes santiagueños (siglos XVI a XIX). Nuevo Mundo Mundos Nuevos. http:// nuevomundo.revues.org/61448. (Última consulta: 10/10/2016) 
Farberman, J. y Ratto, S. 2014. Actores, políticas e instituciones en dos espacios fronterizos chaqueños: la frontera santiagueña y el litoral rioplatense entre 1630-1800. Prohistoria: 22: 3-31.

Jolís, J. 1972 (1789). Ensayo sobre la historia natural del Gran Chaco, Resistencia, Universidad Nacional del Nordeste.

Larrouy, A. 1923. Documentos del AGl para la historia del Tucumán, , Buenos Aires: Rosso, Tomo I (1591-1700).

López de Mariscal, B. y Madroñal, A. (eds.). 2010. Diego de Ocaña, Viaje por el Nuevo Mundo: de Guadalupe a Potosí, 1599-1605, Navarra: Universidad de Navarra.

Lorandi, A.M. 2015. Tukumatukuymanta. Los pueblos del buho. Santiago del Estero antes de la Conquista. Santiago del Estero: Subsecretaría de Cultura de la Provincia.

Lozano, P. 1874 (1745). Historia de la conquista del Paraguay, Río de la Plata y Tucumán. Buenos Aires: Imprenta Popular, Tomo III.

Lozano, P. 1941 (1733). Descripción Corográfica del Gran Chaco Gualamba, Tucumán: Instituto de Antropología.

Levillier, R. 1919. Gobernación del Tucumán. Probanzas de méritos y servicios de los conquistadores. Madrid, Sucesores de Rivadeneyra.

Lucaioli, C. 2005. Los grupos abipones hacia mediados del siglo XVIII, Buenos Aires: Sociedad Argentina de Antropología.

Lucaioli, C. 2011. Abipones en las fronteras del Chaco. Una etnografía histórica sobre el siglo XVIII. Buenos Aires: Sociedad Argentina de Antropología.

Lucacioli, C. y Nacuzzi, L. 2010. Perspectivas metodológicas para el análisis antropológico de las fronteras. En C. Lucaioli y L. Nacuzzi. Fronteras. Espacios de interacción en las tierras bajas del sur de América, Buenos Aires: Sociedad Argentina de Antropología: 1-24.

Maeder, E. 1987. La guerra de fronteras y el reflujo de la conquista rioplatense en el siglo XVII. Boletín de la Academia Nacional de la Historia LX: 131-148.

Maeder, E. 1988. Las dimensiones demográficas del gran Chaco a principios del siglo XVII". Investigaciones y Ensayos 37: 291-316.

Nesis, F. 2005. Los grupos mocoví en el siglo XVIII. Buenos Aires: Sociedad Argentina de Antropología.

Oliveto, G. 2010. Chiriguanos: la construcción de un estereotipo en la política colonizadora del sur andino. Memoria Americana. 18.1:43-69

Palomeque, S. 2009. El Tucumán durante los siglos XVI y XVII. La destrucción de las 'Tierras Bajas' en aras de la conquista de las 'Tierras Altas'. En Yoli Martini, G. Pérez Zavala y Y. Aguilar (comps.). Las Sociedades de los paisajes áridos y semiáridos del centro oeste argentino. Río Cuarto: UNRC: 173-206.

Palomeque, S. 2013. Los caminos del sur de Charcas y de la Gobernación el Tucumán volver durante la expansión inca y la invasión española (siglos XV-XVII), en Sonia Tedeschi et. alli. XIV Encuentro de Historia Regional Comparada (P.I.H.S.E.R.), Santa Fe: Ediciones UNL: 71-100.
Pastells, P. 1912. Historia de la Compañia de Jesús en la provincia del Paraguay (Argentina, Paraguay, Uruguay, Perú, Bolivia y Brasil). Tomo I. Madrid: Librería Victoriano Suárez.

Taboada, C. 2016a. Montículos arqueológicos, actividades y modos de habitar. Vivienda y uso del espacio doméstico en Santiago del Estero (tierras bajas de Argentina). En prensa en Arqueología de la Arquitectura. Madrid.

Taboada, C. 2016b. Arquitectura invisible y "alárabes sin casa": Líneas para pensar modos de vida de las poblaciones prehispánicas de Santiago del Estero. En prensa en Trabajos del XIX Congreso Nacional de Arqueología Argentina. San Miguel de Tucumán.

Taboada, C. 2014. Sequía Vieja y los Bañados de Añatuya en Santiago del Estero. Nodo de desarrollo local e interacción macrorregional. Comechingonia 18: 93-116.

Taboada, C., Angiorama, C., Leiton, D. y López Campeny, S. 2013. En la llanura y los valles... Relaciones entre poblaciones de las tierras bajas santiagueñas y el estado inca: materialidades, elecciones y repercusiones. Intersecciones en Antropología $14: 137-156$.

Taboada, C. y Farberman, J. 2012. Las sociedades indígenas del territorio santiagueño: apuntes iniciales desde la arqueología y la historia. Runa 33: 2:113-132.

Taboada C. y Farberman, J. 2014. Asentamientos prehispánicos y pueblos de indios coloniales sobre el río Salado (Santiago del Estero, Argentina). Miradas dialogadas entre la Arqueología y la Historia. Revista de Arqueología Histórica Argentina y Latinoamericana 8:1:7-44. http://www.arqhistorica.com.ar/ Ediciones4.html (Última consulta: 15/11/2015)

Taboada C. y Farberman, J. 2015. Lasco, Sequía Vieja y la frontera chaqueña del río Salado (Santiago del Estero (Argentina). Propuestas de interpretación interdisciplinaria (arqueologíahistoria). Encuentro Internacional "Arqueología y Etnohistoria en los Andes y Tierras Bajas. Dilemas y miradas complementarias". Cochabamba, 24 al 29 de agosto.

Tomasini, A. 2008. Esteco, el nuevo: contribución al estudio de Nuestra Señora de Talavera de Madrid. 1609-1692. La Plata: Editorial Al Margen.

Tomasini, A. y Alonso, R. 2001. Esteco el Viejo. Breve historia y localización de Nuestra Señora de Talavera. 1566-1609. Salta: Gofica.

Torre Revello, J. 1943. Esteco y Concepción del Bermejo. Dos ciudades desparecidas. Buenos Aires: Peuser.

Vitar, B. 1997. Guerra y misiones en la frontera chaqueña del Tucumán (1700-1767), Madrid: CSIC.

Xarque, F. 1687. Insignes misioneros de la compañía de Jesús en la provincia del Paraguay. Estado presente de sus misiones en Tucumán, Paraguay y Río de la Plata, que comprende su distrito. Pamplona: Juan Micón Impresor.

Zapata Gollán, A. 1966. El Chaco Gualamba y la ciudad de Concepción del Bermejo, Santa Fe. 